\title{
Research on Cultivation of Innovative Management Talents in Universities and Colleges based on Innovation Lab Model
}

\author{
Bao Jianmei \\ School of Economy and Management \\ Shenyang Aerospace University \\ Shenyang City, China
}

\begin{abstract}
Currently universities and colleges are a major place that cultivates the innovative talents as well as a cradle for the growth of innovative talents, playing a critical role in the cultivation of innovative talents. The new innovative lab model aims at transforming talent cultivation model to the innovative talent cultivation model in universities and colleges. This paper mainly studies the innovative lab model, discusses the specific development situations, development characteristics of current innovative lab model along with the specific problems of Chinese universities and colleges in the innovative educational field, puts forward corresponding countermeasures and schemes, and thus provides references for the cultivation of innovative talents in Chinese universities and colleges.
\end{abstract}

Keywords-Management

Innovation;

University

Management; Innovative Talents; Talent Cultivation; Research

\section{INTRODUCTION}

As a basic mission and essential requirement of higher education in China, talent cultivation is also a primary criterion for measuring the teaching quality of higher education in China. Chinese universities and colleges are the main cultivation base for innovative talents in Chinese universities and colleges, playing a critical role in the growth of innovative talents. With the development of society, developed countries have changed the innovation model several years ago, in order to promote and study the innovative lab model. At present, many countries have already promoted their researches on innovative lab. However, innovative lab in China is is still in its infancy. Although initial achievements have been made in the cultivation of innovative talents and establishment of innovative platform, there are still many specific problems to be solved. Different from previous business incubators and university science park models, the innovative lab model pays more attention to the cultivation of innovative talents, which is a new leap-forward new technology and new model. Taking universities and colleges as a carrier, the innovative lab can effectively promote the transformation of scientific and technological achievements, bringing about a very important practical significance to the cultivation of innovative talents.

\section{CHARACTERISTICS AND DEVELOPMENT}

SITUATIONS OF CURRENT INNOVATIVE LAB IN

\section{CHINA}

In recent years, Chinese universities and colleges begin to build innovative lab groups and institutions. Many universities and colleges independently build their own innovative labs. Some universities, colleges, scientific research institutions or enterprise groups jointly build the innovative lab. Several universities and colleges jointly set up the innovative lab, and some governments and schools jointly establish the innovative lab. Regardless of any form, the innovative lab mainly aims at the transformation of innovative model and the cultivation of innovative talents. Through analysis of current innovative lab characteristics, this paper concludes the following main aspects:

The first is externality. At present, innovative lab is a new innovative organization and management model that mainly forms the total factor of innovation, opens the entire chain of innovation, and effectively collaborates with each innovation subject. This innovative organization and management model can effectively break through the barrier among innovation subjects, facilitate to release the capital, talent, technology, information and other innovative elements of each subject, and form the sharing of resources. This innovative lab may integrate innovation, production and application into a whole one, and form a complete industrial chain. As a result, it enables to closely combine with all links, facilitate to promote the transformation of scientific research achievements, and play a very important facilitating role in the development of industrial chain. Due to the coordinated development between universities and colleges, enterprises, research institutions and financial institutions and other related links, the externality of innovative lab has been very widely recognized. Its main performances are as follows: Firstly, the business production and service production put forward new specific requirements for the basic theory, playing a strong role in driving the theoretical innovation of research institutions and universities and colleges. With the development of society and the deepening division of labor, the companies contract their R\&D departments to scientific research institutions for the research and 
development of new products and new technologies, and improve the progress of new products and new technological research of scientific research institutions, universities and colleges, favorable for the final transformation of innovative awareness and innovative ideas into scientific and technological achievements, and favorable for universities and colleges to cultivate more innovative talents with innovative awareness and innovative ideas in the new era.

The second is openness. The innovative lab is composed by many subjects, and each subject is respectively penetrated, causing the exchange between each subject to become more frequent than any period. For example, as a completely open innovative lab, MIT Media Lab has brought together more than 180 companies, government agencies and academic research institutions and sponsors around the world. There are frequent interactions between internal staff of these institutions and innovative lab researchers. Openness promotes the innovative awareness upgrading of innovative researchers and enables them to form more innovative driving forces. In addition, this innovative lab has also established branches in India and Europe, so the innovative research is also characterized by strong extensiveness and globalization.

\section{CuRRENT Problems of InNOVATIVE EDUCATION}

\section{IN CHINESE UNIVERSITIES AND COLLEGES}

In recent years, the innovative education in Chinese universities and colleges has achieved initial success. Many universities and colleges have opened innovative education courses and have accumulated rich experience. Most universities and colleges incorporate the innovative education into efficient school-running system, providing powerful supports in institution building, work instruction, faculty cultivation and many other aspects. Meanwhile, they also develop measures and policy rules for innovative education works. However, there are still shortcomings and specific problems that require timely solution:

First, Chinese universities and colleges need to extend the connotation of innovative talent cultivation. Currently, the innovative education in Chinese universities and colleges mainly take the knowledge imparting and skill training as the subject of education and teaching, lacking the improvement of students' innovative abilities as well as the awareness of compound talent cultivation. Therefore, the Chinese universities and colleges need to break through the traditional educational concept and education model, actively extend the connotation of innovative education, and pay attention to the personality and capability cultivation.

Secondly, the innovative education in China has not been truly incorporated into the university disciplines. Currently, although the Chinese universities and colleges have added the innovative education course, it is still a independently established course in universities and colleges. Consequently, this course is scattered, lacks standard and compulsory properties, is not incorporated into the professional course in universities and colleges, and also does not become a subject of discipline curriculum. Most universities and colleges only open one or two innovative courses, far from the forming a scale and the preset teaching objectives. Compared with the innovative education course in foreign universities and colleges, the course scale is simply pitiful. In ordinary foreign universities and colleges, the innovative education courses may achieve more than a dozen. Therefore, during the development of innovative teaching materials, Chinese universities and colleges should refer to the advanced national textbook compilation experience in the world, develop the boutique innovative education textbook suited to the domestic actual conditions, and provide assistance to the development and extension of innovative education.

Furthermore, the Chinese innovative education system needs further upgrading and transformation. The professional educational model must be transformed into the innovative talent education model, break the educational boundaries, form the collaboration between universities and college and enterprises, implement the innovative education, cultivate high-quality compound innovative talents, truly achieve the innovative lab functions, and highlight the essential characteristics of innovative lab.

\section{RESEARCH ON INNOVATIVE TALENT CULTIVATION}

\section{IN CHINESE UNIVERSITIES AND COLLEGES}

\section{MANAGEMENT}

In Chinese universities and colleges, the innovative education still has the above specific issues. Therefore, it is essential to learn and absorb the advanced international experience, and pay attention to the following aspects in the future development process:

First, strengthen the cultivation of quality to raise awareness of innovative education. In the past university teaching quality management model, a heuristic, exploratory and discussed teaching method that enables students to raise questions, develops ideas, has situation model and bring the students' thinking activities. Traditional single teaching mode can only fix students to be a uniform thinking model, which must be improved for the university teaching management model. To cultivate high-quality professional talents with creative thinking, university teaching management must dig out the students' creative potential. Without innovation, there would be no development. After enhancing the innovative ability of students, it is necessary to produce intriguing plot in the selection of teaching environment, extend the emotions of students, stimulate the resonance of students, and enable students to obtain the specific feelings and correct understanding of the teaching contents, in order to stimulate the thinking ability and exploration ability of students, and improve the stiff old-fashioned situation of teaching quality management model in universities and colleges. With a harmonious classroom atmosphere and a good classroom teaching model, the divergent thinking and innovative ability of students will be improved accordingly. The exam-oriented educational model in universities and colleges cannot stimulate the innovative ability of students. Therefore, it is an important direction for innovative talent cultivation in Chinese universities and 
colleges to abandon the old backward educational concepts, put emphasis on the cultivation of innovative spirits, innovative characters and innovative awareness, and strengthen the quality education and innovative education.

Secondly, strengthen the practical teaching link in Chinese universities and colleges, and promote the cultivation of innovative talents. Practical teaching is an important part of innovative talent cultivation in Chinese universities and colleges, which can help improve the overall quality of students in Chinese universities and colleges and strongly enhance the practical ability of students. For students in universities and colleges, the development of overall ability is particularly important. Excellent professional knowledge and skills are not enough. Only by comprehensively developing the overall ability can students obtain good sense of career achievement and win affirmation from others in the future career. In the traditional teaching system, the overall ability and quality cultivation of students is inadequate, causing the limitation of innovative abilities and cultural connotations of students and a serious impediment to the future development of the students. This requires strengthening the observation and creativity cultivation of students in the teaching management process, focusing on the cultural knowledge cultivation of students, and enabling students to develop comprehensively. Only by improving the overall quality can students develop better in future study and life. For practical teaching, it can be completed through three specific stages like curriculum design, practice and graduation design. At present, to be strong in social life, people should have the relevant overall quality. The professional knowledge is far from enough. The communication skills and organizational skills of students must be exercised through specific practical teaching link, so that the overall quality of students could be developed comprehensively.

Thirdly, strengthen the optimization of knowledge structure of college students and stress humanistic education. In addition to the cultivation of professional knowledge, skills, innovative methods and innovative practical ability, innovative talents must also have comprehensive humanistic knowledge and humanistic quality. Enterprises value the basic knowledge and skills of management talents. However, for the future development of students, humanistic knowledge also plays a crucial concrete role. Therefore, for the design of college curriculum, increased attention must be paid to the humanistic education of college students, the relevant professional courses should be set up, and the high-quality innovative talents with humanistic quality and professional innovative ability who can adapt to the needs of modern society should be cultivated.

Fourthly, open intensive training courses related to innovative thinking and innovative awareness, cultivate the innovative awareness of students through specific intensive courses of innovative education, develop the creativity of students, achieve personalized cultivation, and teach students in accordance of their aptitudes.

\section{CONCLUSION}

In conclusion, the modern society requires college students to have knowledge, capability and overall quality that can adapt to the society. The enterprises focus on the comprehensive quality of innovative talents, require innovative talents not only grasp related professional theoretical knowledge, but also have corresponding adaptability to changes and actual problem-solving ability. Currently the Chinese society is in a critical transition period, so the enterprises have higher new demands over innovative practical ability and innovative awareness of talents than any stage. Therefore, the innovative lab in Chinese universities and colleges must absorb and learn advanced innovative lab experience from the developed countries, actively build a unique innovative talent cultivation and educational model that is suitable for the development of Chinese universities and college, provide high-quality innovative talents with comprehensive practical ability for domestic enterprises, actively explore the interaction and collaboration between universities and enterprises, and thus seek common development.

\section{REFERENCES}

[1] Ershi Qi. Research on Cultivation of Innovative Management Talents in Universities and Colleges based on Innovative Lab Model [J]. Tianjin Science \& Technology, 2014,09:3-6.

[2] Jinkui Li and Li Chen. Research on Effects of Lab Teaching Scientific Research Integration on Innovative Talent Cultivation[J]. University Lab Work Research, 2013,03:107-108.

[3] Xiao Zhang. Research on Innovative Talent Cultivation Model of University Physical Education Major in Shandong[D]. Suchow University, 2013.

[4] Jun Ma. Research on Scientific Innovative Talent Cultivation Model and Methods in Chinese Universities and colleges[D] Hefei University of Technology,2012.

[5] Fei Long and Suhua Zeng. Research on Mechanism of University Lab Management based on Innovative Talent Cultivation[J]. Journal of Changsha Telecommunications and Technology Vocational College,2015,01:101-103.

[6] Fang Meng, Yuxing Qiu and Zhenyu Chen. Research on Curriculum System Setting based on University Innovative Talent Cultivation[J]. Business Economics,2012,09:118-120.

[7] Xianjiang Li. Research on Tactic Knowledge Communication in Elite Innovative Talent Cultivation of University and College Teachers - Case Study of Undergraduate Management Major in Hubei Universities and Colleges[J]. Journal of Chifeng College (Natural Science), 2012,14:69-71.

[8] Yuling Xue. Research on Innovative Talent Cultivation in Universities and Colleges. Economic Research Guide, 2013,08:186-187.

[9] Junzheng Wang and Xiangchao Liu. Research and Practice of University Scientific Research Platform Participation in Undergraduate Innovative Talent Cultivation[J]. Chinese and Foreign Entrepreneurs, 2014, 29:110+113.

[10] Han Huang, Ming Li and Juan Li. Research on Innovative Talent Cultivation Model in Private Universities and Colleges - Case Study of Dual-Capability Management Experimental Class 